\title{
Neurodevelopmental Quotient of Healthy Term Infants at 4 Months and Feeding Practice: The Role of Long-Chain Polyunsaturated Fatty Acids
}

\author{
CARLO AGOSTONI, SABINA TROJAN, ROBER'TO BELIUU,, ENRICA RIVA, ANID \\ MARCELLO GIOVANNINI \\ Department of Pediatrics, University of Milan, The San Paolo Biomedical Institute, \\ Via Antonio di Rudini 8, 20142 Milan, Italy
}

ABSTRACT

\begin{abstract}
A direct influence of dietary long-chain polyunsaturated fatty acids (LC-PUFA) on the developmental quotient (DQ) of the healthy term infant remains unexplored. To test this hypothesis, we designed a prospective study of three types of diet. Twentynine infants received a LC-PUFA-supplemented formula, 31 received a standard infant formula, and 30 infants were breastfed exclusively. Neurodevelopmental response was measured by the Brunet-Lérine psychomotor development test at $4 \mathrm{mo}$. The fatty acid status was also assessed among three diet subgroups (59 subjects) at 4 mo. Formula-fed infants who received LCPUFA supplementation scored significantly higher $(p<0.01)$ on the Brunet-Lézine scale than infants who received the standard formula. Breast-fed infants also performed better than those fed the standard formula. Arachidonic acid and docosahexaenoic acid levels in circulating lipids and erythrocyte phospholipids were higher among breast-fed infants and among the group fed the arachidonic- and docosahexaenoic acid-supplemented for-
\end{abstract}

Experimental evidence is accruing that dietary supplementation or deprivation of the precursors of LC-PUFA (LA and, in particular, ALA) during the early stages of growth affect both LC-PUFA composition in nervous tissue and sensorymotor development (1-4). Decreased levels of DHA (the major $n$-3 LC-PUFA derived from ALA) in the brain tissue of animals fed ALA-poor dicts have been associated with altered learning patterns. Dietary supplementation with preformed DHA increases the DHA levels in animal brain tissue and improves learning skills $(5,6)$

During the perinatal neural growth spurt, the placenta enriches the fetal circulation with AA (the major among $n-6$ LC-PUFA) and DHA in animals as well as humans (7-10). Postnatally, the ideal natural source of these fatty acids is breast milk (11). Varying amounts of LA and ALA are to be

Received April 21, 1994; accepted February 23, 1995

Correspondence: Dr. Carlo Agostoni, Department of Pediatrics, Lniversity of Milan, The San Paolo Biomedical Institute, Via Antonio di Rudini, 8, I-20142 Milan. Italy. mula. These findings are suggestive that formula supplementation with one or both of these fatty acids can benefit term infants in neurodevelopmental performance. (Pediatr Res 38: 262-266, 1995)

DQ, developmental quotient

\section{Abbreviations}

HM, human milk

LC, long chain

PUFA, polyunsaturated fatty acids

LA, linoleic acid or 18:2n-6

ALA, $\alpha$-linolenic acid or 18:3n-3

AA, arachidonic acid or $20: 4 n-6$

DHA, docosahexaenoic acid or $22: 6 n-3$

CI, confidence interval

ANOVA, analysis of variance

found in most standard infant formulas, whereas preformed LC-PUFA are not. Plasma concentrations of LC-PUFA tend to be lower with formula feeding even though precursors be present $(12,13)$. Among dietary LC-PUFA DHA is preferentially channeled into the brain phospholipids of human infants (14). Brain levels of DHA are also associated with erythrocyte DHA levels (15). Correlations between dietary amounts of AA, DHA, and LC-PUFA, their circulating and erythrocyte phospholipid levels, and performance at visual and behavioral assessments have been found by studies on preterm infants, particularly prone to LC-PUFA deficiency (16-19). A recent study found that there was a significant relationship between higher DHA erythrocyte concentrations and performance at visual acuity test among full-term, breast-fed infants (20).

To assess psychomotor development against LC-PUFA status in a population of 4-mo-old term infants, we rated on Brunet-Lézine's neurodevelopmental scale the infants' postural, motor, and social performance in relation to three dietary regimens. 


\section{METHODS}

Study design and subjects. In a controlled, randomized prospective study with a parallel-group design, we surveyed 90 infants born in our clinic between September 1992 and August 1993. Subjects were followed at monthly intervals thereafter until the 4th mo of life. Eligibility was defined by gestational age comprised between the completed 37 th and $42 \mathrm{nd}$ wk, weight at birth appropriate for gestational age according to Battaglia and Lubchenko charts $(21,22)$, Apgar score better than 7 at $5 \mathrm{~min}$, and absence of disease. The definition of gestational age was based on the last menstruation date and confirmed by an ultrasound examination performed within the 20th week. Breast-fed infants were not randomized. Artificially fed infants were randomly allocated (according to a timebalanced randomization table) to groups in a double-blind trial of two types of formula within the 3rd d of life. One group of infants (F1) was fed an experimental LC-PUFA-supplemented formula, another group (F2) received a standard commercially available formula lacking in LC-PUFA, but including their polyunsaturated precursors LA and ALA (Table 1). A third group (HM) included infants fed exclusively on their mother's milk. The formulas were supplied by Milupa AG of Friedrichsdorf, FRG, and differed only in fat content and quality. Both formulas contained $1.5 \mathrm{~g}$ protein, $7.2 \mathrm{~g}$ lactose, $3.6 \mathrm{~g}$ fat per $100 \mathrm{~mL}$ (energy: $67 \mathrm{kcal} / 100 \mathrm{~mL}$ ). The lipid mixture of the experimental formula included LC-PUFA of the $n-3$ and $n-6$ series. The fat blend was derived from palm oil, coconut and palm kernel fats, soybean oil, sunflower oil for its parent PUFA, and evening primrose oil for its $\gamma$-linolenic (18:3n-6)containing triglycerides. Egg lipids were added to provide LC-PUFA-containing phospholipids and triglycerides.

Protocol. Parents gave their informed consent for enrollment, neurodevelopmental testing, and blood sampling and analysis. The Departmental Ethics Committee approved the study aims and design. Parents were also requested to adhere strictly to the prescribed diet (except on contrary medical advice). Parental age, education, and occupation status (classified according to the Italian Census Institute) (23) and infant birth order were recorded.

Brunet-Lézine test. The Italian edition of the graded psychomotor developmental test by $\mathrm{O}$. Brunet and I. Lézine for French children (24) was used to rate global neurodevelopment

Table 1. Fat composition of the two study formulas and HM

\begin{tabular}{cccc}
\hline $\begin{array}{c}\text { Fatty acids } \\
(\mathrm{g} / 100 \mathrm{~g} \text { fat })\end{array}$ & $\mathrm{F} 1$ & $\mathrm{~F} 2$ & European $\mathrm{HM}^{*}$ \\
\hline Saturated & 55.1 & 48.2 & $39.0-51.3$ \\
C18:1n-9 & 28.7 & 38.8 & $34.2-44.9 \dagger$ \\
$18: 2 n-6$ & 10.8 & 11.1 & $6.9-16.4$ \\
$18: 3 n-6$ & 0.30 & & $0.1-0.9$ \\
$18: 3 n-3$ & 0.73 & 0.70 & $0.7-1.3$ \\
$20: 4 n-6$ & 0.44 & & $0.2-1.2$ \\
$20: 5 n-3$ & 0.05 & & $0.0-0.6$ \\
$22: 6 n-3$ & 0.30 & & $0.1-0.6$ \\
\hline
\end{tabular}

F1 = LC-PUFA-supplemented formula, F2 = standard formula. As the raw materials used in the lipid blend are from natural sources, fatty acid content may vary.

* Bibliographical Ref. 11.

† Given as total monounsaturated fatty acids. at 4 mo. This test is commonly used in the Romance languagespeaking nations of Western Europe. Brunet-Lézine's psychometric approach, like that of other tests, ultimately derives from Gesell's developmental schedules (25) and is adapted to the age range of our population. It explores four developmental areas: posture and gross motor function, adaptation and fine motor function, social reactions, and language. Scores on Brunet-Lézine's neurodevelopmental scale rate the performance of items of graded difficulty. Item batches of 10 are assigned to 1 mo of real age. Real age is defined as the postnatal age in weeks corrected by subtracting $40 \mathrm{wk}$ from the postconceptional age $(24,26)$. Developmental age is calculated as the sum of credits earned with the performance of each item in the battery. A credit counts as 1 and represents $3 \mathrm{~d}$ of life. The DQ is then calculated according to the following formula:

$$
\frac{\text { Developmental age }}{\text { Real age }} \times 100 \text {. }
$$

Brunet and Lézine standardized the tests for each grade by comparing the rate of success $(\%)$ in the performance of each item. A success rate of $>68 \%$ defines an item as characteristic of each monthly stage of development. This empirical classification is then statistically validated (24).

All tests were carried out by the same monitor (S.T.).

Fatty acid analysis. Whole venous blood from the antecubital vein was diluted in an acid-citrate-dextrose-solution (71 $\mathrm{mmol} / \mathrm{L}$ citric acid, $85 \mathrm{mmol} / \mathrm{L}$ sodium citrate, $111 \mathrm{mmol} / \mathrm{L}$ dextrose; 1:9 vol/vol) and centrifugated at $1250 \mathrm{rpm}$ for 18 min, and plasma rich in platelets was removed. Erythrocytes were resuspended in acid-citrate-dextrose and further centrifugated (four cycles). After osmotic shock the erythrocyte membranes were washed at high speed centrifugation and the final pellet was stored at $-80^{\circ} \mathrm{C}$ until analyzed. The plasma for lipid extraction was obtained by centrifugation of plasma rich in platelets at $3000 \mathrm{rpm}$ for $15 \mathrm{~min}$ after removal of the platelet pellet. Plasma lipids were extracted by stepwise addition of 1 $\mathrm{mL}$ water, $4 \mathrm{~mL}$ methanol, and $8 \mathrm{~mL}$ chloroform to $0.5 \mathrm{~mL}$ of plasma. After phase separation, the organic layer was collected and solvents evaporated under $\mathrm{N}_{2}$ (27). Lipids were extracted from erythrocyte membranes with chloroform-methanol $(2: 1$, $\mathrm{vol} / \mathrm{vol}$ ) (28) and $\mathrm{KCl} 0.88 \%$ in the presence of the antioxidant butylated hydroxytoluene $(5 \mu \mathrm{g} / \mathrm{mL})$. Plasma lipid classes and erythrocyte phospholipids were separated by thin-layer chromatography (thin-layer chromatography silica gel plates 60 , supplied by Merck of Darmstadt, FRG) using $n$-hexane/diethyl ether/acetic acid (80/20/1, vol/vol) as developing solvents (29).

Fatty acid methyl esters were prepared by acid-catalyzed transmethylation with methanolic hydrochloride (Supelco, Bellefonte, PA) and separated by gas-chromatography (Carlo Erba model 4160, supplied by Fisons Instruments of Rodano, Italy, equipped with a flame ionization detector) and a fused silica capillary column (Supelco Omegawax 320, $30 \mathrm{~m}$ in length, $0.32-\mathrm{mm}$ internal diameter, and $0.25 \mu \mathrm{m}$ thick film), using a temperature program rising from 130 to $230^{\circ} \mathrm{C}$ by increments of $3^{\circ} \mathrm{C} / \mathrm{min}$. Separate peaks from the detector output were identified by using pure reference compounds (Supelco) and were expressed as weight \%. Nonadecanoic acid 
(19:0) was added as internal standard to the sample before methyl ester preparation. The following fatty acids were identified for most plasma lipid classes and erythrocyte phospholipids: 16:0, 16:1n-7, 18:0, 18:1n-9, 18:2n-6, 18:3n-6, 18:3n-3, $20: 3 n-6,20: 4 n-6,20: 5 n-3,22: 4 n-6,22: 5 n-6,22: 5 n-3,22: 6 n-3$. Fatty acid fractions of less than $0.2 \%$ were not considered.

Statistics. In planning trial size, the probability $\beta$ of a type II error fixed at 0.10 was considered acceptable to estimate clinical response with a DQ magnitude variation of $10 \%$ admissible for a clinically meaningful difference between groups. The number of subjects for the purpose of the study was calculated as 24 in each group. We then oversampled up to 30 . With 24 subjects per feeding group, the differences between groups of the average fatty acid parameters yield a probability $\beta$ of between 0.03 and 0.08 for a type II error measured as AA and DHA variation of 30 and $50 \%$, respectively $(12,13)$. The data are expressed as mean \pm SD. The $95 \% \mathrm{CI}$ were calculated at 4 mo for the variables under study. Differences between DQ scores and fatty acid levels were tested by ANOVA. Categorical variables for socioeconomic indicators were compared using the $\chi^{2}$ test. Comparison between group means was tested by the Newman-Keuls method. The limit of significance was set at 0.05 . All statistical analyses were performed on the SPSS/PC+ statistical package (SPSS/ PC+3.1; SPSS Inc., Chicago, IL).

\section{RESULTS}

Ninety subjects were recruited and thus allocated: 29 in group F1 (15 boys, 14 girls), 31 in F2 (16 boys, 15 girls), and 30 subjects in the HM group (13 boys, 17 girls). At 4 mo, 86 subjects underwent Brunet-Lézine's neurodevelopmental test. Four subjects (two girls in both F1 and F2) were too agitated and could not be assessed. Table 2 sets out the characteristics of the 86 infants.

The mean Brunet-Lézine score of our sample was 101 (SD, $11 ; 95 \% \mathrm{CI}=99-103)$. The minimum score reached was 80 and the maximum 136. The percentile cutoffs were obtained at the following points: $5 \%, 82 ; 10 \%, 86 ; 25 \%, 94 ; 50 \%, 101$;
$75 \%, 107 ; 90 \%, 115 ; 95 \%, 122$. The distribution of these observations falls within the distribution curves described by Brunet and Lézine, who report that $50 \%$ of their observed DQ scores in 725 subjects fall between 90 and 110 (6 subjects $>125$; 7 subjects $<80$; interobservation correlation of $r=$ 0.85 , with different monitors) (24). A significant scoring difference can be seen between the enriched formula and the standard formula-fed groups (Table 3). Breast-fed infants also scored higher than infants fed the standard formula. No difference for parental and socioeconomic factors was found between the three infant groups. The time-balanced randomization tables removed intergroup differences due to parental occupation and education status (data not shown).

Consent for blood sampling was obtained from the parents of 15 infants $(50 \%)$ in $\mathrm{HM}, 23$ in $\mathrm{F} 1(85 \%)$, and 19 in $\mathrm{F} 2$ (65\%). The subjects not sampled did not present differences in basic characteristics and $D Q$, when compared with infants of the same groups who underwent blood testing. Among infants who underwent blood sampling, the breast-fed and the supplemented formula-fed groups present AA and DHA levels in their circulating and erythrocyte lipids that are higher than those of infants fed the standard formula (Table 4). Only erythrocyte AA levels were found to be higher among infants in the supplemented formula-fed group, whereas they were similar in the breast-fed and the standard formula-fed groups.

\section{DISCUSSION}

This is the first study that directly connects the psychomotor performance of full-term infants at 4 mo with LC-PUFA of both the $n-6$ and $n-3$ series integrated in a formula regimen. We speculated that if an enhanced neurodevelopmental response could be elicited among infants either breast-fed or fed a formula supplemented with LC-PUFA, this could be the effect of the presence of these fatty acids in their diet and could also account for their higher performance at psychomotor tests.

The preferential uptake by the developing brain of preformed, longer chain fatty acids with a higher degree of unsaturation $(30,31)$ can alter the lipid composition of neuron

Table 2. Group characteristics (mean $\pm S D$ ) of the 86 infants who underwent the $D Q$ testing

\begin{tabular}{|c|c|c|c|c|c|}
\hline & \multirow[b]{2}{*}{$\mathrm{F} 1(n=27)$} & \multirow[b]{2}{*}{$\mathrm{F} 2(n=29)$} & \multirow[b]{2}{*}{$\mathrm{HM}(n=30)$} & \multicolumn{2}{|c|}{ ANOVA by milk } \\
\hline & & & & $F$ & $p$ \\
\hline Weight at birth (g) & $3168 \pm 448$ & $3299 \pm 453$ & $3431 \pm 501$ & 2.24 & 0.11 \\
\hline Parity $(n)$ & $1.4 \pm 0.6$ & $1.6 \pm 1.1$ & $1.6 \pm 0.5$ & 0.61 & 0.54 \\
\hline Mother's age (y) & $32.4 \pm 5.7$ & $31.5 \pm 5.5$ & $29.4 \pm 5.9$ & 2.10 & 0.12 \\
\hline Father's age (y) & $34.5 \pm 5.1$ & $33.1 \pm 4.8$ & $32.1 \pm 6.4$ & 1.36 & 0.26 \\
\hline Gestational age (wk) & $39.0 \pm 1.3$ & $39.4 \pm 1.4$ & $39.0 \pm 1.1$ & 0.95 & 0.39 \\
\hline Postconceptional age at DQ (wk) & $56.6 \pm 1.5$ & $56.9 \pm 1.5$ & $56.7 \pm 1.7$ & 0.27 & 0.76 \\
\hline Real age at $D Q(w k)$ & $16.6 \pm 1.5$ & $16.9 \pm 1.5$ & $16.7 \pm 1.7$ & 0.45 & 0.63 \\
\hline
\end{tabular}

$\overrightarrow{F 1}=$ LC-PUFA-supplemented formula, $\bar{F} 2=$ standard formula.

Table 3. $D Q($ mean $\pm S D)$ at 4 mo

\begin{tabular}{|c|c|c|c|c|c|}
\hline & \multirow[b]{2}{*}{ F1 $(n=27)$} & \multirow[b]{2}{*}{ F2 $(n=29)$} & \multirow[b]{2}{*}{$\mathrm{HM}(n=30)$} & \multicolumn{2}{|c|}{ ANOVA (by milk) } \\
\hline & & & & $F$ & $p$ \\
\hline DQ & $105.3 \pm 9.4^{*}$ & $96.5 \pm 10.9 \dagger$ & $102.2 \pm 11.5^{*}$ & 4.93 & 0.009 \\
\hline $95 \% \mathrm{Cl}$ & $101.8-108.8$ & $92.6-100.4$ & $98.1-106.3$ & & \\
\hline
\end{tabular}

Different superscripts $\left(\dagger,{ }^{*}\right)$ indicate significantly different $(p<0.05)$ values. $\mathrm{F} 1=$ LC-PUFA-supplemented formula, $\mathrm{F} 2=$ standard formula. 
Table 4. Mean levels ( $\pm S D$ ) of fatty acids (FA) (\% wt/wt) in lipid classes

\begin{tabular}{|c|c|c|c|c|c|}
\hline $\mathrm{FA}$ & $\mathrm{F} 1(n=21)$ & $\mathrm{F} 2(n=23)$ & $\operatorname{HM}(n=15)$ & $F$ & $p$ \\
\hline \multicolumn{6}{|c|}{ FA in plasma, total lipids } \\
\hline $20: 4 n-6$ & $7.0 \pm 1.5 \dagger$ & $4.4 \pm 1.1^{*}$ & $8.5 \pm 2.4 \ddagger$ & 30.4 & $<0.001$ \\
\hline $95 \% \mathrm{CI}$ & $6.3-7.6$ & $3.9-4.8$ & $7.2-9.7$ & & \\
\hline $22: 6 n-3$ & $2.1 \pm 0.6 \dagger$ & $0.6 \pm 0.1^{*}$ & $2.7 \pm 0.8 \$$ & 78.8 & $<0.001$ \\
\hline $95 \% \mathrm{CI}$ & $1.8-2.4$ & $0.55-0.65$ & $2.3-3.1$ & & \\
\hline \multicolumn{6}{|c|}{ FA in plasma phospholipids } \\
\hline $20: 4 n-6$ & $9.0 \pm 1.4 \dagger$ & $6.2 \pm 1.3^{*}$ & $10.8 \pm 2.1 \div$ & 41.6 & $<0.001$ \\
\hline $95 \% \mathrm{CI}$ & $8.4-9.6$ & $5.6-6.8$ & $9.7-11.9$ & & \\
\hline $22: 6 n-3$ & $2.7 \pm 0.6 \dagger$ & $0.9 \pm 0.3^{*}$ & $2.8 \pm 0.8 \dagger$ & 73.6 & $<0.001$ \\
\hline $95 \% \mathrm{CI}$ & $2.4-3.0$ & $0.8-1.0$ & $2.4-3.2$ & & \\
\hline \multicolumn{6}{|c|}{ FA in plasma cholesterol esters } \\
\hline $20: 4 n-6$ & $5.5 \pm 1.6 \dagger$ & $3.9 \pm 1.5^{*}$ & $6.9 \pm 2.0 \ddagger$ & 15.0 & $<0.001$ \\
\hline $95 \% \mathrm{CI}$ & $4.8-6.2$ & $3.3-4.5$ & $5.9-7.9$ & & \\
\hline \multicolumn{6}{|c|}{ FA in erythrocyte phospholipids } \\
\hline $20: 4 n-6$ & $16.3 \pm 1.2 \dagger$ & $15.1 \pm 1.8^{*}$ & $14.6 \pm 2.3^{*}$ & 4.61 & 0.01 \\
\hline $95 \% \mathrm{CI}$ & $15.8-16.8$ & $14.3-15.9$ & $13.4-15.8$ & & \\
\hline $22: 6 n-3$ & $4.1 \pm 0.6 \dagger$ & $1.8 \pm 0.4^{*}$ & $4.1 \pm 1.1 \dagger$ & 75.1 & $<0.001$ \\
\hline $95 \% \mathrm{CI}$ & $3.8-4.4$ & $1.6-2.0$ & $3.5-4.7$ & & \\
\hline
\end{tabular}

Different superscripts $\left(\dagger,{ }^{*}, \ddagger\right)$ indicate significantly different $(p<0.05)$ values. F1 $=$ LC-PUFA-supplemented formula, F2 $=$ standard formula.

membranes and can also modulate brain neurotransmitter activity. A short-term effect of dietary LC-PUFA on the structural modification of membranes and the performance of sensorymotor function has indeed been experimentally and clinically demonstrated (4-6, 16-19). Sensory-motor performance was assessed to rate the neurodevelopmental response as DQ scores on Brunet-Lézine scale in contrast to earlier visual acuity (16, $19)$ or developmental studies $(17,18)$ of preterm infants who were fed $n$-3 LC-PUFA and whose response was assessed by different methods. HM is a natural source of LC-PUFA, and enriching a formula patterned on HM with AA and DHA also significantly correlates with higher DQ scores that quantify this response. Circulating and erythrocyte phospholipid levels of AA and DHA were also significantly higher.

Brunet-Lézine scales (like other psychometric tests) quantify variations from the theoretical mean of an empirical developmental sequence. The infant DQ derived from psychometric tests shows a poor relationship with the intelligence quotient of older children $(24,26)$. Then, that psychomotor infant development at $4 \mathrm{mo}$ is directly influenced by the dietary intake of both AA and DHA does not ensure a predictive value of these results for childhood trends, and even less for later childhood development and beyond. The problem of the persistence of differences between groups supplied with $n$-3 LC-PUFA and controls has been addressed by animal studies $(4,6,32)$ and is currently the focus of studies on preterm infants $(16,19)$. Animals lacking dietary LC-PUFA in the early stages of growth show an age-related recovery of their structural lipid composition with a rehabilitation diet $(4,6,32)$. The possibility of a parallel functional improvement is still the object of debate. Midterm observations on animals and preterm infants are also often conflicting $(4,6,16,19,32)$.

The specific effect and nutritional mode of action of dietary AA and DHA in relation to neurodevelopmental response and dietary intervention planning are open questions for further study. The diet groups we studied are currently being followed and we will report on the medium- and long-term implications.
Acknowledgments. The authors thank Maria Grazia Bruzzese, Ph.D., and Norma Bianchi, Ph.D., for contributions to the laboratory tests. We also thank Gabriel R. Bouygue for his critical advice on the manuscript.

\section{REFERENCES}

1. Yamamoto N, Saitoh M, Moriuchi A, Nomura M, Okuyama H 1987 Effect of dietary $\alpha$-linolenate/linoleate balance on brain lipid composition and learning ability of rats. J Lipid Res 28:144-151

2. Coscina DV, Yehuda S, Dixon LM, Kish SJ, Leprohon-Greenwood C 1986 Learning is improved by a soybean oil diet in rats. Life Sci 38:1789-1794

3. Yehuda S 1989 Behavioral effects of dietary fats. In: Chandra RK (ed) Health Effects of Fish and Fish Oils. ARTS Biomedical Publishers, St. John's, Newfoundland, pp 327-335

4. Enslen M, Milon H, Malnoe A 1991 Effect of low intake of $n$-3 fatty acids during development on brain phospholipids, fatty acid composition and exploratory behavior in rats. Lipids 26:203-208

5. Fujimoto K, Yao K, Miyazawa T, Hirono H, Nishikawa M, Kimura S, Maruyama K, Nonaka M 1989 The effect of dietary docosahexaenoate on the learning ability of rats. In: Chandra RK (ed) Health Effects of Fish and Fish Oils. ARTS Biomedical Publishers, St. John's, Newfoundland, pp 275-284

6. Wainwright PE, Huang YS, Bulman-Fleming B, Mils DE, Redden P, McCutcheon D 1991 The role of $n-3$ essential fatty acids in brain and behavioral development: a cross-fostering study in the mouse. Lipids 26:37-45

7. Clandinin MT, Chapel JE, Leong S, Heim T, Swyer PR, Chance GW 1980 Intrauterine fatty acid accretion rates in human brain: Implications for fatty acid requirements Early Hum Dev 4:131-138

8. Crawford MA, Hassam AG, Williams G 1976 Essential fatty acids and fetal brain growth. Lancet 1:452-453

9. Friedman Z, Danon A, Lamberth EK 1978 Cord blood fatty acid composition in infants and in their mothers during the third trimester. J Pediatr 92:461-466

10. Hoving EB, van Beusekom CM, Nijeboer HJ, Muskiet FA 1994 Gestational age dependency of essential fatty acids in cord plasma cholesterol esters and triglycerides. Pediatr Res 35:461-469

11. Koletzko B, Thiel I, Abiodun PO 1992 The fatty acid composition of human milk in Europe and Africa. J Pediatr 120:S62-70

12. Clark KJ, Makrides M, Neumann MA, Gibson RA 1992 Determination of the optimal ratio of linoleic acid to $\alpha$-linolenic acid in infant formulas. J Pediatr 120:S151-158

13. Ponder DL, Innis SM, Benson JD, Siegman JS 1992 Docosahexaenoic acid status of term infants fed breast milk or infant formula containing soy oil or corn oil. Pediat Res 32:683-688

14. Farquharson J, Cockburn F, Patrick WA, Jamieson EC, Logan RW 1992 Infant cerebral cortex fatty acid composition and diet. Lancet 340:810-813

15. Makrides M, Neumann MA, Byard RW, Simmer K, Gibson RA 1994 Fatty acid composition of brain, retina and erythrocytes in breast- and formula-fed infants. Am J Clin Nutr 60:189-194

16. Uauy RD, Birch DG, Birch EE, Tyson JE, Hoffman DR 1990 Effect of dietary omega- 3 fatty acids on retinal function of very-low-birth weight neonates. Pediatr Res 28:485-492

17. Bjerve KS, Brubakk AM, Fougner KG, Johnsen H, Midthjell K, Vik T 1993 Omega-3 fatty acids: Essential fatty acids with important biological effects, and serum phos- 
pholipid fatty acids as markers of dietary omega-3 fatty acid intake. Am J Clin Nutr 57(suppl):801S-806S

18. Carlson SE, Werkman SH, Peeples JM, Cooke RJ, Wilson WM 1992 Plasma phospholipid arachidonic acid and growth and development of preterm infants. In Koletzko B, Okken A, Rey J, Salle B, Van Biervlict JP (eds) Recent Advances in Infant Feeding. Thieme Medical Publishers, New York, pp 22-27

19. Carlson SE, Werkman SH, Rhodes PG, Tolley EA 1993 Visual-acuity developmen in healthy preterm infants: Effect of marine oil supplementation. Am J Clin Nutr $58: 35-42$

20. Makrides M, Simmer K, Goggin M, Gibson RA 1993 Erythrocyte docosahexaenoic acid correlates with the visual response of healthy, term infants. Pediatr Res 34:425427

21. Battaglia FC, Lubchenko LO 1967 A practical classification of newborn infants by weight and gestational age. J Pediatr 71:159-163

22. Lubchenko LO, Hansman C, Boyd E 1966 Intrautcrine growth in length and head circumference as estimated from live births at gestational age from 26 to $42 \mathrm{wk}$. Pediatrics 37:403-408

23. Twelfth General Census of the Italian Population, 1983. Central Statistics Institute (ISTAT), Rome

24. Brunet O, Lézine I 1966 Le développement psychologique de la première enfance, 2nd Ed (Italian translation, 1967). Presses Universitaires de France, Paris
25. Gesell A, Amatruda C 1947 Developmental Diagnosis. Harpers \& Brothers, New York

26. Amiel Tison C, Grenier A 1980 Evaluation neurologique du nouveau-né et du nourrisson. Masson, Paris

27. Galli C, Edwards KGD, Paoletti R 1970 Serum phospholipid alterations and their control by chlorohenoxyisobutyrate and betabenzolbutyrate in puromycin aminonucleoside-induced nephrotic syndrome in the rat. Life Sci 9:523-534

28. Folch J, Lees M, Stanley GHS 1957 A simple method for the isolation and purification of total lipids from animal tissues. J Biol Chem 226:497-509

29. Colowick SP, Kaplan NO 1969 Thin-layer chromatography of lipids. Mcthods Enzymol 14:530-609

30. Sinclair AJ 1975 Incorporation of radioactive polyunsaturated fatty acids into liver and brain of developing rats. Lipids 10:175-184

31. Anderson GJ, Connor WE 1988 Uptake of fatty acids by the developing rat brain. Lipids 23:286-290

32. Connor WE, Neuringer M, Lin DS 1990 Dictary effects on brain fatty acid composition: The reversibility of $n-3$ fatty acid deficiency and turnover of docosahexaenoic acid in the brain, erythrocytes, and plasma of rhesus monkeys. J Lipid Res 31:237247 